\title{
Genetic analysis of two Iranian patients affected with cystinosis identified a novel CTNS mutation: case report
}

\author{
fatemeh sarlaki ${ }^{1}$ and Saeid Morovvati ${ }^{2}$ \\ ${ }^{1}$ Shahid Beheshti University of Medical Sciences \\ ${ }^{2}$ Islamic Azad University Tehran Medical Sciences
}

January 3, 2022

\begin{abstract}
Two Iranian patients presented in this study was suffering from cystinosis diagnosed based on their clinical symptoms and laboratory tests. The variations c.257_258delCT and c.323delA in the CTNS gene found in them are frameshifts and truncating mutations that affect product function and result in the signs and symptoms of cystinosis.
\end{abstract}

\section{INTRODUCTION}

Cystinosis (OMIM \# 219800), an autosomal recessive disease, is caused by the CTNS gene mutation. This gene encodes cystinosin, which transports the lysosomal free cystine. In cases where cystinosin is deficient, lysosomal free cystine accumulates throughout the body[1-3].

Cystinosin has additional roles, such as trafficking of the vesicles in the epithelial cells lining the proximal tubules, biogenesis of lysosomes, autophagy regulation, and mTOR signaling[4].

Systemic complications associated with cystinosis include the Fanconi syndrome, reduced functional activity of gonads, diabetes mellitus, hypothyroidism, exocrine pancreatic enzymes shortage, calcification of blood vessels, crystalline keratopathy, retinal blindness, involvement of the central nervous system, benign increased intracranial pressure [5], and occasionally gastrointestinal symptoms[6].

Based on the disease severity, three different clinical types of cystinosis are dependent on the cysteine accumulation degree and the age at presentation. In the most sever and common case, in terms of severity, nephropathic cystinosis occurs in infancy. The second type is the late-onset adolescent form (intermediate), also known as the nephropathic juvenile cystinosis. The third type is the benign adult form, also known as the ocular non-nephropathic form[7].

The CTNS gene, situated on chromosome 17p13, normally has 12 exons. Ever since the gene was discovered in 1998, more than 148 different CTNS pathogenic and deleterious mutations have been reported in the Ensemble database and various articles[1,8].

In this study, we reviewed the genetic basis of cystinosis and investigated two Iranian cases affected by cystinosis one of which revealed a novel mutation in the CTNS gene.

\section{CASE PRESENTATION}

Clinical information was collected by reviewing the medical records. Evaluation of history, clinical manifestations, and laboratory findings of symptomatic patients A and B were performed. Patients A and B were 9, and 11-year-old females with renal insufficiency living in the Iranian capital city of Tehran diagnosed with suffering from cystinosis on the basis of their clinical symptoms and laboratory tests. Data were reviewed from birth until December 2020. After genetic counseling and assessing the familial pedigree (Fig. 
1), both patients' parents gave their informed consent before being included in this investigation. Extraction of genomic DNA from whole blood was done using standard extraction methods. Mutation analysis and sequencing of the 10 CTNS gene exons were performed. The exon amplification was done via PCR. The products were purified on an agarose gel and directly sequenced with similar PCR primers.

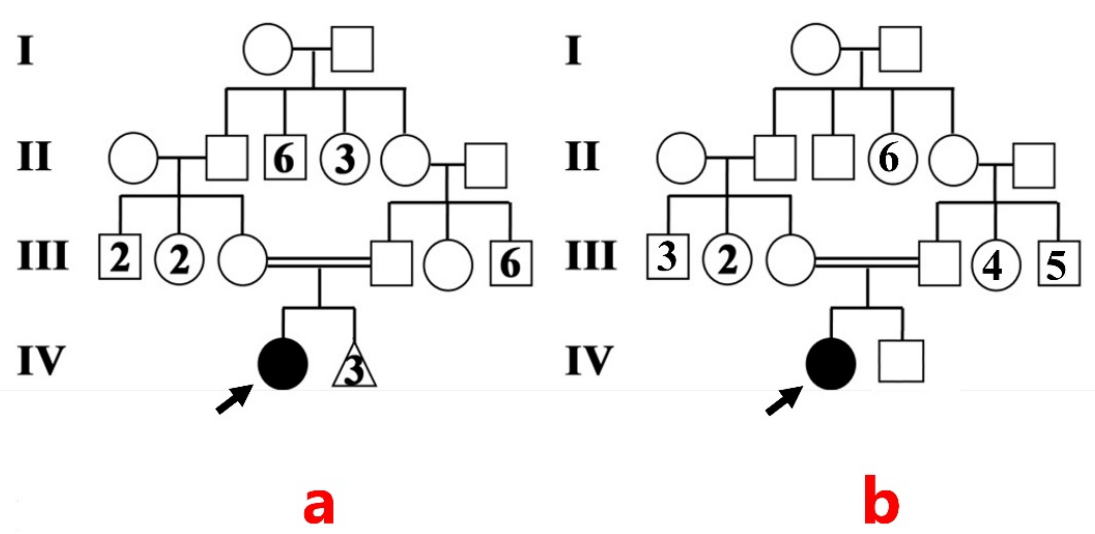

Fig. 1. (a) Family pedigree of patient A, (b) Family pedigree of patient B.

The probands described in this study had clinical manifestations, which conform to the diagnostic cystinosis such as atrophy of the proximal convoluted tubules and renal stones, severe thirst and dehydration, failure to thrive, hematuria, proteinuria, glycosuria, phosphaturia, decreased serum $\mathrm{Na}, \mathrm{K}, \mathrm{Ca}, \mathrm{P}, \mathrm{Mg}$ and urea, metabolic acidosis, and decreased skin and hair pigmentation. Their physical examination showed growth retardation with a history of teething delay.

Furthermore, both cases unusually did not show photophobia. Slit-lamp evidenced cystine crystals in the cornea of patients. Skeletal surveys showed mild rickets in case A. They both attended a normal school at a normal age level, so their intelligence was normal. Exon analysis in our patients detected a novel homozygous DNA variation c.257_258delCT (p.Ser86PhefsTer38) in exon 6 of the CTNS gene in patient A, and another homozygous DNA variation, c.323delA (p.Q108RfsTer10), in the same exon in patient B. These variations were detected in their parents in heterozygous states (Fig. 2 and 3). 

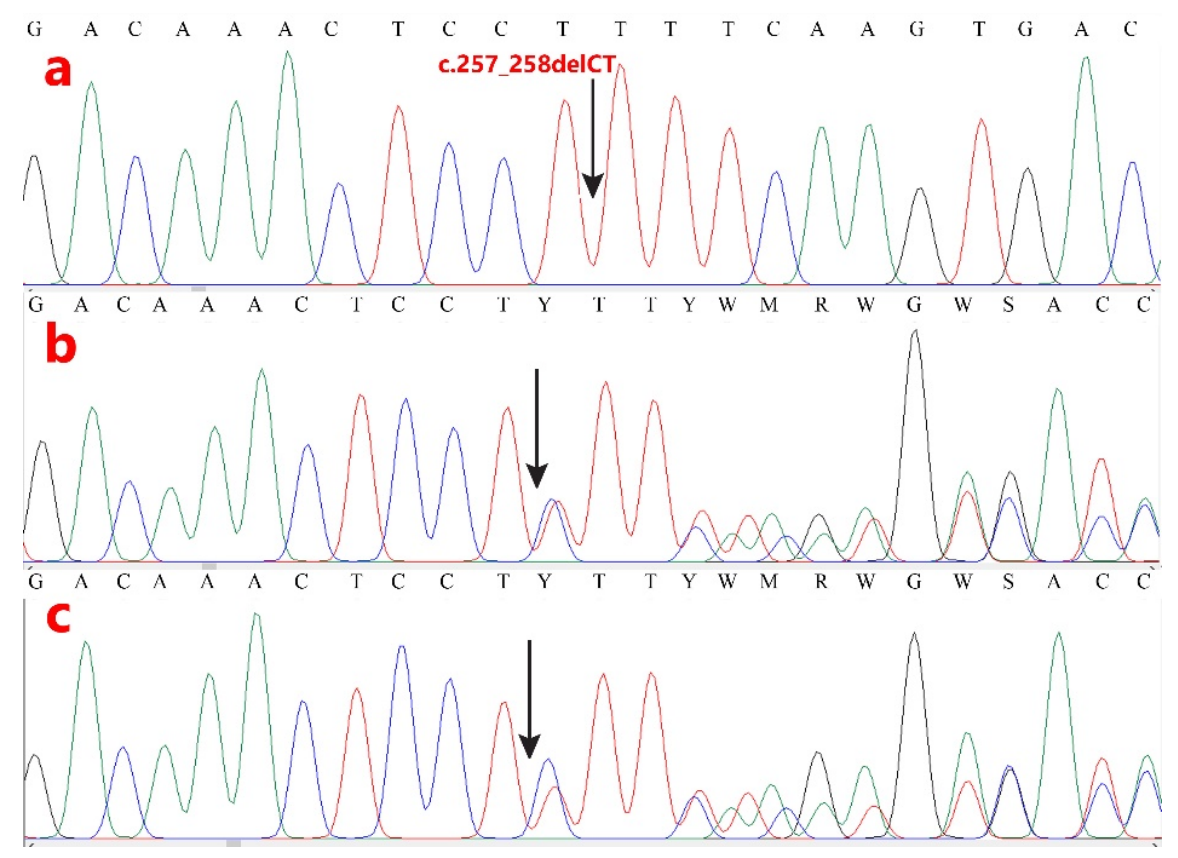

Fig. 2. The chromatogram shows the mutation c.257 258delCT in the CTNS gene; (a) a homozygous state in patient $\mathrm{A}$, ( $\mathrm{b}$ and $\mathrm{c}$ ) heterozygous states in her parents.

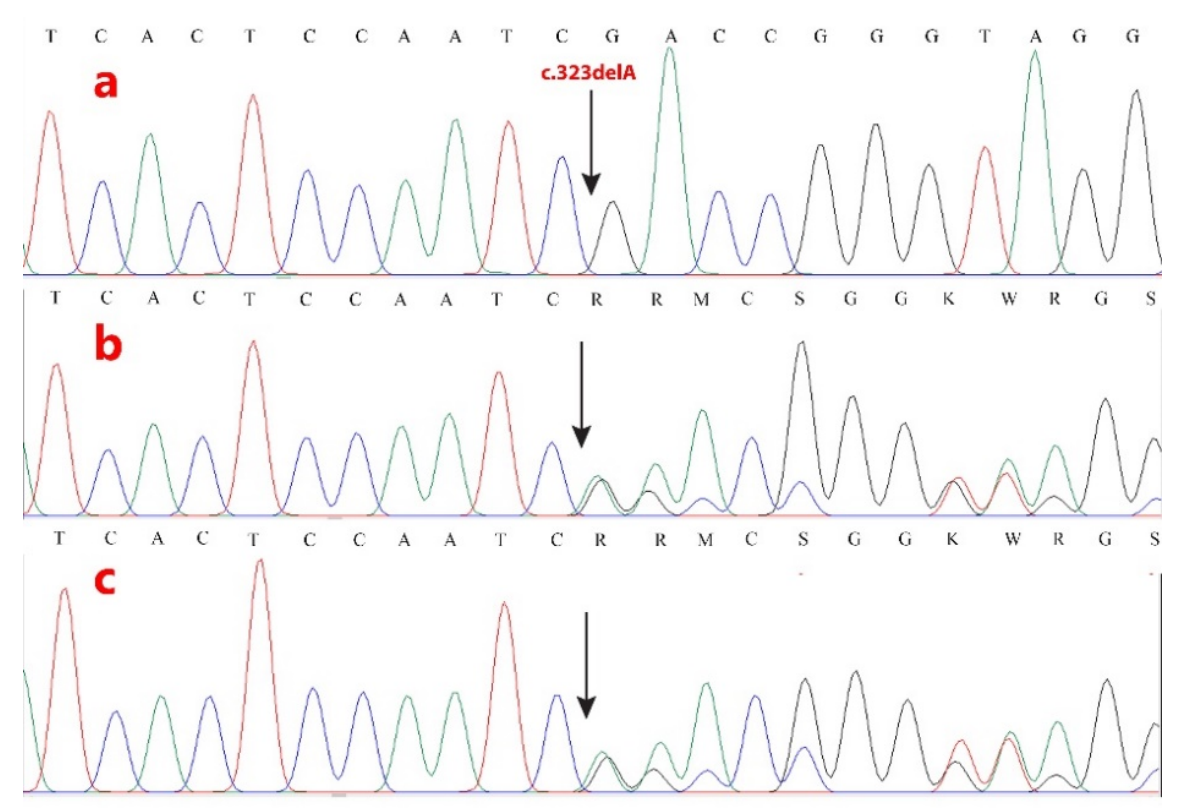

Fig. 3. The chromatogram shows the mutation c.323delA in the CTNS gene; (a) a homozygous state in patient $\mathrm{B},(\mathrm{b}$ and $\mathrm{c})$ heterozygous states in her parents.

\section{DISCUSSION}

The incidence of cystinosis is approximately 1 in 100,000 to 200,000 newborns[3]; however, this frequency is expected to be higher in populations in which consanguinity is prevalent, such as North Africa, Pakistan, 
the Middle East, Turkey[9,10], and Iran[11].

The most prevalent causative mutation in cystinosis in northern Europe and North America is a large 57-kb deletion[12-15]. In contrast, this deletion is absent in cases reported from Turkish[10,16,17], Egyptian[18], and Saudi Arabian populations[19]. In Iran, a patient was reported with this mutation. Hence this 57-kb deletion is extremely rare in cases reported from in the Middle East[20].

The c.681G $>$ A (p.E227E) mutation is the most frequent mutation in Iran[21] and also in the Middle East[18].

In Canada's French population, a nonsense mutation, p.W138*, accounts for cystinosis's most common mutation[22].

The CTNS gene mutations were studied in 28 Iranian patients aged 1-17, affected by nephropathic cystinosis. In $50 \%$ of patients (14 individuals), the mutations were identified in exon 6 , among which $7.18 \%$ (5persons) were detected to have novel homozygous deletions, all of which cause the cystinosin protein to be truncated prematurely. The c.323delA (p.Q108RfsX10) mutation was also detected in 3 cases[23].

In 2018 Bastug et al. reported a novel CTNS homozygous splice mutation, c.853-1G $>$ A, in a rare nephropathic cystinosis case, initially presenting with Bartter syndrome features[24].

\section{CONCLUSIONS}

The variations c.257_258delCT and c.323delA in the CTNS gene found in this study are frameshifts and truncating mutations that affect product function and result in the signs and symptoms of cystinosis. As far as we know, the identified mutation in our case $\mathrm{A}$ has not been reported before and can be considered a novel mutation. The detected mutation in our case B has been only repoeted in 3 other Iranian patients, showing that this mutation can be considered a specific one related to the Iranian population. The present finding will be useful for carrier detection in the family and other patients with similar disease manifestations and genetic diagnosis.

\section{ACKNOWLEDGMENTS}

We thank the patients and their parents for their collaborative attitude and for consent to publish the findings. We are also grateful to the Rasad Pathobiology and Genetic Laboratory staff for their close collaboration.

\section{CONFLICTS OF INTEREST}

The authors have no conflicts of interest to declare.

\section{AUTHOR CONTRIBUTIONS}

SM drafted the work, provided approval for publication of the content, and collected the detailed information. FS is responsible for designing this study, acquisition, analysis, and interpretation of data for the work. FS, and SH: revised the draft critically. All authors read and approved the final manuscript.

\section{ETHICS APPROVAL}

Written consent for participating in this study was obtained from the parents of both patients. The study was performed in accordance with the principles of the Helsinki Declaration.

\section{INFORMED CONSENT}

Informed consent was obtained from all individual participants included in the study.

\section{DATA AVAILABILITY STATEMENT}

Some data regarding the above case are present within this manuscript and authors have access to all data for this case report.

\section{ORCID}

Fatemeh Sarlaki https://orcid.org/0000-0003-4698-0932 
Saeid Morovvati https://orcid.org/0000-0001-8838-1044

\section{REFERENCES}

1. Town M, Jean G, Cherqui S, Attard M, Forestier L, Whitmore SA, Callen DF, Gribouval O, Broyer M, Bates GP, van't Hoff W. A novel gene encoding an integral membrane protein is mutated in nephropathic cystinosis. Nature genetics. 1998 Apr;18(4):319-24.

2. Kalatzis V, Antignac C. Cystinosis: from gene to disease. Nephrology Dialysis Transplantation. 2002 Nov 1;17(11):1883-6.

3. Gahl WA, Thoene JG, Schneider JA. Medical progress: cystinosis. The New England journal of medicine. 2002;347(2):111-21.

4. Cherqui S, Courtoy PJ. The renal Fanconi syndrome in cystinosis: pathogenic insights and therapeutic perspectives. Nature Reviews Nephrology. 2017 Feb;13(2):115.

5. Gahl WA, Balog JZ, Kleta R. Nephropathic cystinosis in adults: natural history and effects of oral cysteamine therapy. Annals of internal medicine. 2007 Aug 21;147(4):242-50.

6. NAKHAEI S, HOUMAN N, Otukesh H. Gastrointestinal manifestations of nephropathic cystinosis in children.

7. Wilmer MJ, Schoeber JP, van den Heuvel LP, Levtchenko EN. Cystinosis: practical tools for diagnosis and treatment. Pediatric nephrology. 2011 Feb;26(2):205-15.

8. McDowell GA, Gahl WA, Stephenson LA, Schneider JA, Weissenbach J, Polymeropoulos MH, Town MM, van't Hoff W, Farrall M, Mathew CG. Linkage of the gene for cystinosis to markers on the short arm of chromosome 17. Nature Genetics. 1995 Jun;10(2):246-8.

9. Hutchesson AC, Bundey S, Preece MA, Hall SK, Green A. A comparison of disease and gene frequencies of inborn errors of metabolism among different ethnic groups in the West Midlands, UK. Journal of medical genetics. 1998 May 1;35(5):366-70.

10. Topaloglu R, Gulhan B, İnözü M, Canpolat N, Yilmaz A, Noyan A, Dursun İ, Gökçe İ, Gürgöze MK, Akinci N, Baskin E. The clinical and mutational spectrum of Turkish patients with cystinosis. Clinical Journal of the American Society of Nephrology. 2017 Oct 6;12(10):1634-41.

11. Sadeghipour F, Basiratnia M, Derakhshan A, Fardaei M. Mutation analysis of the CTNS gene in Iranian patients with infantile nephropathic cystinosis: identification of two novel mutations. Human genome variation. 2017 Oct 5;4(1):1-6.

12. Forestier L, Jean G, Attard M, Cherqui S, Lewis C, van't Hoff W, Broyer M, Town M, Antignac C. Molecular characterization of CTNS deletions in nephropathic cystinosis: development of a PCR-based detection assay. The American Journal of Human Genetics. 1999 Aug 1;65(2):353-9.

13. Shotelersuk V, Larson D, Anikster Y, McDowell G, Lemons R, Bernardini I, Guo J, Thoene J, Gahl WA. CTNS mutations in an American-based population of cystinosis patients. The American Journal of Human Genetics. 1998 Nov 1;63(5):1352-62.

14. Touchman JW, Anikster Y, Dietrich NL, Maduro VV, McDowell G, Shotelersuk V, Bouffard GG, Beckstrom-Sternberg SM, Gahl WA, Green ED. The genomic region encompassing the nephropathic cystinosis gene (CTNS): complete sequencing of a 200-kb segment and discovery of a novel gene within the common cystinosis-causing deletion. Genome research. 2000 Feb 1;10(2):165-73.

15. Kalatzis V, Nevo N, Cherqui S, Gasnier B, Antignac C. Molecular pathogenesis of cystinosis: effect of CTNS mutations on the transport activity and subcellular localization of cystinosin. Human molecular genetics. 2004 Jul 1;13(13):1361-71. 
16. Topaloglu R, Vilboux T, Coskun T, Ozaltin F, Tinloy B, Gunay-Aygun M, Bakkaloglu A, Besbas N, Van Den Heuvel L, Kleta R, Gahl WA. Genetic basis of cystinosis in Turkish patients: a single-center experience. Pediatric Nephrology. 2012 Jan;27(1):115-21.

17. Mason S, Pepe G, Dall'Amico R, Tartaglia S, Casciani S, Greco M, Bencivenga P, Murer L, Rizzoni G, Tenconi R, Clementi M. Mutational spectrum of the CTNS gene in Italy. European journal of human genetics. $2003 \mathrm{Jul} ; 11(7): 503-8$.

18. Soliman NA, Elmonem MA, van den Heuvel L, Hamid RH, Gamal M, Bongaers I, Marie S, Levtchenko E. Mutational spectrum of the CTNS gene in Egyptian patients with nephropathic cystinosis. InJIMD Reports, Volume 142014 (pp. 87-97). Springer, Berlin, Heidelberg.

19. Aldahmesh MA, Humeidan A, Almojalli HA, Khan AO, Rajab M, Al-Abbad AA, F. Meyer B, Alkuraya FS. Characterization of CTNS mutations in Arab patients with cystinosis. Ophthalmic genetics. 2009 Nov $1 ; 30(4): 185-9$.

20. Najafi M, Tamandani DM, Azarfar A, Bakey Z, Behjati F, Antony D, Schüle I, Sadeghi-Bojd S, Karimiani EG, Schmidts M. A $57 \mathrm{kB}$ genomic deletion causing CTNS loss of function contributes to the CTNS mutational spectrum in the middle east. Frontiers in pediatrics. 2019 Mar 21;7:89.

21. Shahkarami S, Galehdari H, Ahmadzadeh A, Babaahmadi M, Pedram M. The first molecular genetics analysis of individuals suffering from nephropatic cystinosis in the Southwestern Iran. Nefrologia. 2013 Jan 1;33(3):308-15.

22. Brasell EJ, Chu L, El Kares R, Seo JH, Loesch R, Iglesias DM, Goodyer P. The aminoglycoside geneticin permits translational readthrough of the CTNS W138X nonsense mutation in fibroblasts from patients with nephropathic cystinosis. Pediatric nephrology. 2019 May;34(5):873-81.

23. Ghazi F, Hosseini R, Akouchekian M, Teimourian S, Kachoei ZA, Otukesh H, Gahl WA, Behnam B. CTNS molecular genetics profile in a Persian nephropathic cystinosis population. Nefrología (English Edition). 2017 May 1;37(3):301-10.

24. Bastug F, Nalcacioglu H, Ozaltin F, Korkmaz E, Yel S. Nephropathic cystinosis mimicking bartter syndrome: a novel mutation. Iranian journal of kidney diseases. 2018;12(1):61. 